\title{
Youth Participation in Home Care for the Elderly
}

Rosimere Ferreira Santana*, Márcia Teixeira de Souza, Fátima Helena do Espírito Santo, Edmundo Drummond Silva and Nathália Henrique Martins

Universidade Federal Fluminense, Médico-Cirúrgico - MEM, Rua Dr Celestino, Brazil

\begin{abstract}
This article aims to define the participation of young people (ages 14 through 19) in elderly care and to analyze young people's thoughts about aging, care, and intergenerationality. Study quantitative-qualitative cross-sectional, included 343 youths with elderly care participation. The major activities were bureaucratic $(12.2 \%)$, medications and food $(14.3 \%)$ and companionship (14.6\%). The perception regarding "taking care of someone" was positive in $80.8 \%$; when the genders were compared, men and women were found to view caregiving roles differently $(p=0.048)$. The young people providing home care for the elderly is increasing in contemporary society, highlighting the necessity of gerontological education.
\end{abstract}

Keywords: Intergenerational relationships; Caregiving - informal; Family issues

\section{Introduction}

Demographic data show a decrease in birth rates and the likelihood of a more even age distribution [1]. This trend requires social adjustments and adaptive measures to suppress the need for elderly care and the financial dependence that is caused by the later inclusion of youths in the labor market [2-5]. Consequently, there is a need for studies that track these changes and their health and societal implications.

When young people and the elderly live together within families, intergenerational support is mainly provided by combining and redistributing personal resources, including time and finances [6,7].

In addition to financial dependence, multigenerational cohabitation is associated with changes in family structure, such as divorce, same-sex marriage, the growing role of women in the labour market $[2,8-10]$, and the need for emotional or health care support.

According to the literature, family members are generally the first choice to care for vulnerable individuals, and women, children and spouses are chosen primarily because personal and emotional relationships over time tend to determine interpersonal relationships as humans grow older [10-13].

Nevertheless, cohabitation allows for the exchange of experiences and memories between the elderly and youths and can help change young people's attitudes toward the elderly and vice-versa [6].

Research has also shown a trend in Latin America, Asia, Japan and Korea towards the increased cohabitation of elderly parents and their children, either because of financial constraints or companionship or for emotional, physical and/or financial support [7].

However, with changes in the family structure, the likelihood that multiple generations will be involved in family care increases [14-16]. Although family care can take many forms, the data from Alwin, Öberg and Krevers [17] show that the majority of cases involve dependent elderly or grandparents caring for their grandchildren. The studies find various forms of care and stress, depending on the family's ethnic background [18-21] hence, the importance of relating intergenerational care to different cultures.

The definition of a generation may not simply be those belonging to the same age group but rather groups of people who have lived through the same individual, historical, cultural or social moments that persist throughout the life continuum $[4,8]$. The dialogue created by the perceived age-specific and/or stereotypical traits of two or more generations living together allows individuals to incorporate individuals of a different age into their own timeframe, thus searching for new social connections that are independent of age [22].

Within a family environment, care depends upon the emotional relationships that family members develop by living together and through their experiences with intergenerational interactions, available resources and societal preparation $[6,9,23,24]$.

In this context, it is essential for us to understand that intergenerational relationships form youths' perspectives on assisting with developing health care and educational practices that fit social, cultural, and demographic trends.

The hypothesis was therefore formulated that intergenerational care provides the opportunity for interactions between adolescents and older generations.

\section{Objective}

Determinate the participation of young people (ages 14 through 19 ) in elderly care and to analyse their thoughts about aging, care and intergenerationality.

\section{Method}

\section{Design and Ethical Considerations}

We chose to perform a quantitative-qualitative cross-sectional observational study within the context of complementarity given the recommendations of previous studies on adolescents that such studies guarantee the appeal of the research and the comprehension of the questionnaire and minimize the probability of evasive responses $[25,26]$.

The use of these tools was justified via previous contact with the

*Corresponding author: Rosimere Ferreira Santana, Universidade Federa Fluminense, Médico-Cirúrgico-MEM, Rua Dr Celestino, 74, 24020091, Niteroi, Rio de Janeiro, Brazil, Tel: +5521994639624; E-mail: rosifesa@gmail.com

Received April 27, 2015; Accepted May 27, 2015; Published May 29, 2015

Citation: Santana RF, De Souza MT, Santo FHE, Silva ED, Martins NH (2015) Youth Participation in Home Care for the Elderly. J Gerontol Geriat Res S3:006. doi:10.4172/2167-7182.S3-006

Copyright: (c 2015 Santana RF, et al. This is an open-access article distributed under the terms of the Creative Commons Attribution License, which permits unrestricted use, distribution, and reproduction in any medium, provided the original author and source are credited. 
supervisors at the authors' teaching institutions and by the favorable opinion of the local university's Research Ethics Committee under Protocol Number CAAE-00030258326-10.

\section{Settings and Samples}

The study was performed in the city of Vassouras, which is located in the South Fluminense region of the state of Rio de Janeiro. The city includes approximately $13 \%$ elderly and $24.5 \%$ adolescents, who are enrolled in official schools, out of a total population of 34,495 inhabitants occupying an area that is approximately $67 \%$ urban [1].

The city, which is home to a university, has a transient and economically diverse population that enables academics and those with specialized skills to come together. The city also has 31 elementary schools with 5,937 students and 10 middle schools with 1,269 students [1].

We had four middle schools for this research at the Urban Area. We assumed that the majority of students in middle school would be aged between 14 and 19 years $(n=1,269)$. We also estimated that the sampling error $\left(\mathrm{E}_{0}\right)$ would be $5 \%$, based on the formula for infinite populations that has been proposed by Barbetta [26], which led to the selection of at least 304 subjects:

$$
\mathrm{n}=\frac{\mathrm{N} \cdot \mathrm{n}_{0}}{\mathrm{~N}+\mathrm{n}_{0}} \quad \text {, where } \mathrm{n}_{0}=\frac{1}{E_{0}^{2}}
$$

$\mathrm{N}=$ population size, $\mathrm{n}=$ sample size and $\mathrm{n}_{0=}$ initial approximation of the sample size.

For convenience and to meet institutional and ethical standards, the final sample of 343 adolescents was selected and referred to the study by school administrators. The following inclusion criteria were applied: students between ages 14 and 19 who had agreed to participate in the study, had written informed consent forms signed by legal guardians and who fully participated in the proposed activity.

\section{Data Collection}

The data were collected via a partially structured questionnaire that contained 20 closed questions related to the care the respondent provided for others, organized on a Likert-type scale (never, rarely, sometimes, often, always), and via a checklist-type instrument about the meaning of and synonyms for "care" (for example, provide support, watch, be attentive, etc.). There were also four open questions about whether the respondent takes care of someone at home and his/her relationship to this person, the respondent's expectations about aging, his/her preparation for longevity and whether anyone had talked to the respondent about aging.

As this was an adolescent population, we opted for an instrument that is appropriate for teenagers. Therefore, questions were adopted that would encompass both subjective and objective aspects to avoid evasive and incomplete answers. Similarly, the length, ease of language and comprehensibility to teenagers of the questions were taken into consideration. The questionnaire was based on the theoretical frameworks of the life-span theory and intergenerational care, was elaborated upon to include sociodemographic data and was completed by the adolescents themselves.

The pretest of the instrument validation was conducted with 37 adolescents in a school that was not included in the sample. An assessment was performed to understand the magnitude of the responses and whether adequate content validity was obtained, and adjustments were made to the presentation of the written language.

The data were collected from June to November 2011 by a team of four researchers who were trained in project planning meetings during the development of the data collection script and during a pilot test in a school that was not selected for the study (data collected at this school were not included in the final dataset).

\section{Data Analysis}

The organization and processing of the quantitative data began with the creation of spread sheets for each school. The participants were given a code to assure their anonymity. The first spread sheet included data on age, sex, family income and religion. The second spread sheet contained answers regarding the synonymy of "care", aging and elderly care. Each spread sheet was created separately, as the first required a binomial response with a 1 for each selected term and a 2 for each unselected term, while the other questions were given a score of 0 to 4 points on the Likert-type scale based on the respondents' answers.

For the inferential analysis of the interrelated interpretations of the pre-established protocol frameworks, descriptive analyses of the raw data were performed using Statistical Package for the Social Sciences (SPSS) Version 13.0 (IBM, Armonk, NY, USA) and Microsoft Excel (Microsoft, Redmond, WA, USA). The analyses focused on frequency distributions and the interdependency of two variables using chisquared or Fisher's exact tests. Differences with a p-value $<0.05$ were considered to be significant.

Open questions were transcribed in their entirety onto forms that were organized by school and labelled with the interviewees' identification codes. The expressions used in the statements were maintained to aid the interpretation process and to emphasize the vocabulary or apparent thoughts expressed in the participants discourse in connection to the study's goals.

During the exchange, verbal data collection was representative because it revealed systematized values and structures and signs and social measures that had been previously standardized in the individual's discourse [27]. The historical circumstances and contexts of the adolescent participants' speech were extracted from this representation of the exchange.

After identifying the consistencies and inconsistencies in the participants' discourse, the discourse data were triangulated with the quantitative data.

\section{Results}

\section{Sample Characterization}

The sample of 343 youths was divided into two groups according to age: Group I included 199 (58.01\%) participants aged 14 or 15 years old and Group II included 144 (41.99\%) participants aged 16 to 19 years. The difference in group size was not significant.

The majority of the respondents $(235,68.51 \%)$ were female, and 108 (31.40\%) were male. A chi-squared test showed that there was a significant difference between the number of males and females in the two age groups ( $\mathrm{p}$-value $=0.01$ ).

The family incomes were divided into two groups: $75.8 \%$ (260) of the participants came from families who earned up to twice the monthly minimum wage (approximately US $\$ 650$ ), while $18.7 \%$ (64) of the respondents reported that they had family incomes between two and five times the minimum wage (between US\$650 and US\$1,725).

The majority of the participants reported their religion as Catholic $(n=152,44.3 \%)$, followed by Evangelicals $(n=105,30.6 \%)$. An analysis 
of the joint distribution of gender and religion revealed a significant difference ( $\mathrm{p}=0.0000)$; more female participants were Evangelical, and more male participants were Catholic.

\section{Youth Participation in Caregiving}

A total of 103 of 343 adolescents (30.1\%) stated that they took care of someone at home, and this number was considered relevant. The proportions of male and female youths who reported taking care of someone at home were not significantly different, despite the lower number of male respondents $(\mathrm{p}=0.427)$.

The participants' perception about "taking care of someone" was positive in $84(80.8 \%)$ of the responses, and only 20 participants $(19.8 \%)$ had a negative opinion of taking care of family members. However, when the genders were compared, 87 (84.78\%) women and 70 (68.75\%) men had a positive perception, which suggests that men and women view caregiving roles differently $(\mathrm{p}=0.048)$.

\section{Youth participation in elderly care: secondary care}

Only eight $(7.9 \%)$ participants in the sample reported providing care without an adult present, thus being the main person responsible for another person's personal care and security (i.e., acting as primary caregivers).

Another 23 (22.2\%) participants were secondary caregivers (i.e., they support the primary caregiver in assisting with the instrumental activities of daily living and providing companionship).

Accordingly, the adolescents showed little participation in the direct care of the elderly person's health in tasks such as hygiene $(n=4,4.1 \%)$ or dressing $(\mathrm{n}=4,4.1 \%)$. Instead, the adolescents were more involved in providing medicine and food $(\mathrm{n}=15,14.3 \%)$, remembering the elderly family member's medication schedule $(\mathrm{n}=14,13.7 \%)$ and taking them

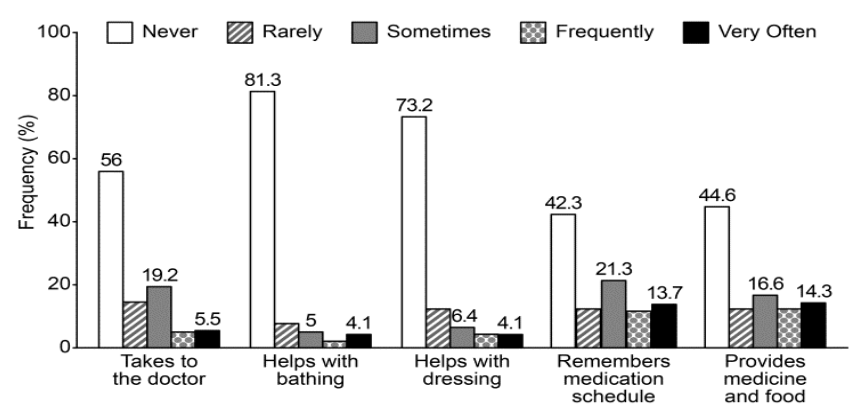

Figure 1: Direct care of the elderly person's health in tasks.

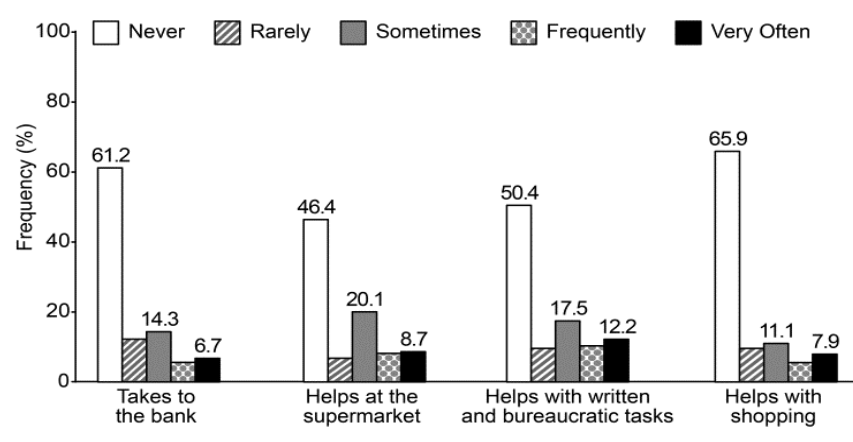

Figure 2: Helping with domestic activities.

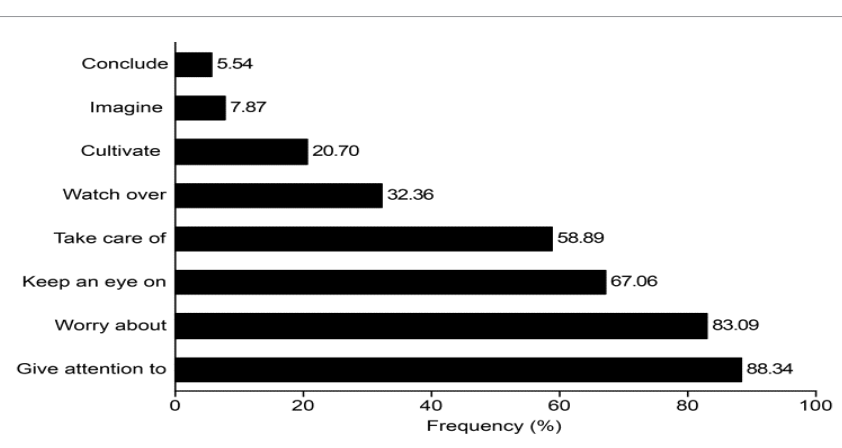

Figure 3: Analyzing the answers.

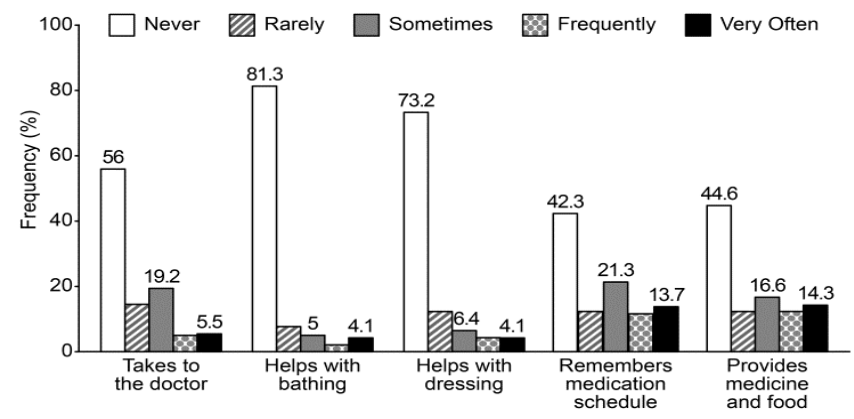

Figure 4: Activities that promote Intergenerational exchange involving Adolescents.

to the doctor $(\mathrm{n}=5,5.5 \%)$, as shown in Figure 1 .

Activities that create an awareness and validation of solidarity in the role of caregiving, such as providing company for an elderly family member, encourage a situation of co residence for the adolescent caregiver. Because an emotional relationship has been established between the youths and the elderly, the adolescents remain as secondary caregivers, as indicated by the following response:

I have two mentally ill uncles at home, but I do not take care of them. I just check on them from time to time, which is good because I like them a lot. (EC 9, male, 17 years old).In cases in which the elderly person's health was debilitated, the young person performed domestic chores. This work may lead to both positive and negative feelings. The health team should consider this fact and provide ways for the caregiver to address the situation and avoid related stress: I care for my grandpa. It is both good and bad (RF 56, male, 18 years old). I care for my grandma. For me, it is already a routine, so it is normal. (TC 83, female, 16 years old).In this manner, the adolescent may perform caregiving chores along with domestic and social ones. These chores require having decision-making skills and organizing the daily routine because the youths should not stop performing tasks that are normal for their age group, as explained here: When she was sick, I also took care of her and the domestic chores (TC 75, female, 16 years old).I used to care for my grandma. In the beginning, I got upset because I wanted to go out but had to stay with my grandma (EC 71, female, 15 years old). Figure 1 shows the most frequent care activities, which include helping with written and bureaucratic tasks $(\mathrm{n}=12,12.2 \%)$, helping at the supermarket $(n=9,8.7 \%)$, shopping $(n=8,7.9 \%)$ and taking the elderly person to the bank $(n=7,6.7 \%)$.

Regarding helping with domestic activities, in some cases, the adolescents slept near the elderly person $(n=15,14.6 \%)$, performed 
domestic chores $(\mathrm{n}=14,13.4 \%)$ and kept the elderly person company over the weekend ( $\mathrm{n}=9,8.5 \%)$, as shown in Figure 2 .

\section{The Meaning of "Care"}

Analysing the answers concerning the meaning of "care" (Figure 3), "attention" (88.34\%), "worry" (83.09\%), "attentiveness" (67.06\%) and "taking care of" (58.89\%) can be highlighted. The responses were not significantly different between the age groups or genders.

However, the option "watch over" was an exception. Male youths selected "watch over" as a synonym for "care" more often (40.75\%) than the females (28.75\%).

Additionally, 23.76\% of those participants who cared for someone selected "watch over", while $37.00 \%$ of those who did not care for someone selected it.

In-home care refers to care that requires time and effort at home. However, cohabitation allows for the exchanging of experiences, and the young caregivers consequently involve themselves in a complex and interdependent social network. Thus, the youths (mainly females), focus on reciprocity, solidarity, confidence and responsibility in their daily routines: I took care of my grandma. It was special for me to care for someone who had cared for me (RF 16, female, 16 years old). I care for my mother. It is an act of love, as she always cared for me (PS 40, female, 14 years old). I care for my grandpa and grandma. I will help them until the day God takes them away. Not only them but also other elderly people who are in need; it feels very good (RF 39, female, 18 years old). Cohabitation between different age groups promotes the inversion of social roles and family emotional relationships and can lead to attitudes of cooperation and care between the grandparent and the grandchild, generating feelings of reciprocity between generations.

\section{The Meaning of Intergenerational Exchange}

Figure 4 shows the distribution of activities that promote intergenerational exchange involving adolescents. Half of the respondents $(54.5 \%)$ stated that they "care for someone as I would like to be cared for", which indicated that they become involved in the present care activities with a perspective toward the future that has been developed throughout their lives.

In addition, the acts of learning from $(37.3 \%)$ or teaching (24\%) the elderly were viewed as reciprocal activities that helped the elderly person and the adolescent grow, as demonstrated by the following:

I take care of him thinking about the future, how I am caring for him now and how it could be me in the future. The good thing about sleeping in the same room as him is that we talk at night. I talk about motorcycles, cars, trails I have travelled, where I have been, etc., and he tells stories about where he worked and many other things. (EC 42, male, 16 years old)

I simply live with my grandma to keep her company. I sometimes lose my patience with her because she thinks I am still a child and keeps saying things like "Be careful when you cross the street", but I like it (RF 15 , female, 16 years old).

Bidirectional parental care between grandparent and grandchild includes the transmission of values between generations that live together as well as discussions about responsibilities in formal and informal care during the aging process, as observed in the following response:

I live with my grandpa. For me, it is a very good experience. I have affection and attention. There are times when we play together, talk and even go out together (EC 46, male, 15 years old).

I need to behave myself (i.e., I need to treat the elderly of today how I want to be treated when I am old) (TC 12, female, 17 years old).

It is traditionally believed that elderly people have wisdom, and one of the expected activities of the elderly is sharing their life experiences with younger generations, as shown by the fact that $28 \%$ of the adolescents reported that they "hear stories from the elderly".

The adolescents reported both positive and negative experiences about elderly care; there are temporary and individual differences, as the following response shows:

It is a new experience, but it is difficult at times, as the elderly have different ideas than we are used to (TC 50, female, 16 years old).

At times, I lose my patience with her because she likes to solve her problems her own way. (RF 15, female, 16 years old)

Intergenerationality may help eliminate family patterns that are usually negative; therefore, rejections and conflicts are not repeated. Bad experiences with the aging of family members can generate bad attitudes toward the elderly among youths. This reality emphasized the need to engage in dialog about aging in our society with young people in public spaces, such as schools.

\section{Discussion}

As expected, because of epidemiological and cultural trends, the majority of young people who care for elderly people also live with them, creating multigenerational homes $[1,10]$. These homes result from changes in family structure, low income and late entry to the labor market and facilitate multigenerational cohabitation.

Public policy discussions about the future of "grandchildren caring for their grandparents" [28] center on both health care reform and on raising and educating adolescents with an intergenerational perspective; however, in different cultures, both situations can coexist in the same space $[17,29,30]$ or even estimate a trend of "grandchildren caring for their grandparents".

There are implications for the priority of intergenerational perspectives on care practices in gerontology. One must analyze not just the elderly care itself but also the family's involvement in the maintenance practices of social and daily activities. Preparing children and young people for aging and formalizing the educational curriculum for teaching gerontology, known as "informal education in gerontology”, are still limited practices in Brazil $[26,28]$.

Parent-child relationships are not completely comparable to grandparent-grandchild relationships. Tompkins believes that there is a third type of relationship to account for, i.e., grandparents caring for grandchildren. The relationship between grandchildren and the grandparents they care for has also been described [3,7], indicating that youths are taking on caregiver roles in various cultures and societies, as this study found.

The Policies for an Aging World [31], such as the Brazilian policies on aging [32], place the responsibility for elderly care on families; nonetheless, social support for family care is lacking [33].

To create a society that is prepared to accommodate an aging population [31,32], guidelines often recommend adopting policies to develop human resources and spaces that enable intergenerational 
encounters and maintain healthy habits (i.e., helping the elderly to maintain physical and functional health may entice young people to do the same).

Although we found a predominance of females among the adolescents providing in-home elderly care (similarly to what has been found among adults) [34], we found that the profile of the caregivers was not particularly different between genders, except that the young women participated in domestic activities more often, and the young men were more likely to help with bureaucratic tasks. Additional studies are needed to confirm these findings, as is a more in-depth analysis of the differences in the profile of those who are cared for in terms of gender, level of dependence, religion and perception of care $[8,15]$.

Helping with written and bureaucratic tasks was identified by Kelley as one of the major activities that are performed by children caring for the elderly. Such assistance also helps youths develop skills for performing instrumental activities; however, this result was not clearly shown in this study, indicating a need for further studies.

Home care activities that do not aid in transitioning from adolescence to adulthood are noted in relation to the lack of opportunities to fulfill everyday social roles. This reality is part of the give and take in a family setting [3].

Because adolescents prioritize their own physiological and social needs, the exclusive care of the elderly is precluded $[3,35]$, but intergenerational relationships and helping with secondary care are not, per se. Therefore, longitudinal studies are necessary to better track these tendencies.

The results of this study corroborate those reported by Schmidt, including demonstrations of love and concern by grandchildren for their grandparents through care and attention. The emotional involvement of caring for another person requires consistency and presence along with availability and the control of schedules and tasks [36].

Thus, at times, care includes watching over the elderly, as described by the majority of young men and those participants who reported caring for someone at home. This result was recorded as a significant gender difference in relationships between youngsters and grandparents.

There are also the effects of having different age groups living together, which allow for the adaptation of social roles to be subjected to the give and take, particularly family member roles that have been standardized by Western culture and are transmitted from parents, uncles/aunts and grandparents [37].

Therefore, there is a need to develop new values and behaviors that break with tradition because when families are committed to an individualistic ideal, as is becoming commonplace in contemporary families, we have the opposite situation in which a needs mechanism is competing with hierarchical and protective values [38].

In terms of individual convenience, learning between generations is unequal and specific and results in both good and bad experiences. For adolescents, living with an elderly person can be difficult, and promoting harmonious relationships between generations should be a goal of every gerontologist.

Chua, et al. conducted a study on the effects of video-game play on intergenerational perceptions among youths and elderly participants and demonstrated a practice that could be adopted to promote intergenerational interactions, benefiting both participants. Such initiatives should be encouraged in gerontology to the detriment of the exclusive participation in activities of the elderly.
Therefore, beginning with the idea of establishing an equilibrium between affection and reciprocity within a normative structure of caring and being cared for (a condition of human survival that is established by acts of honor and love) [39], attitudes are transformed into reciprocity in caregiving relationships, independent of age groups.

\section{Conclusions}

The results of this study support the purpose of promoting intergenerationality because of the increased participation of young people in elderly care, summarized as the development of human gerontology resources that promote an intergenerational perspective and delineate the implications for the sustainability of the elderly in society as well as their coexistence with other age cohorts.

At its core, this study details young students' perceptions about aging and their role in in-home care as secondary caregivers. This role is mainly taken on by female adolescents and includes helping an elderly family member with instrumental activities of daily living and providing companionship. In this way, by virtue of their availability and presence, the youths participate in an informal support network [40].

As for the young people's thoughts about aging, care and intergenerationality, it was observed that they are not well prepared for aging. Therefore, considering that the assumptions for the promotion of active aging begin from conception, these adolescents need to be encouraged regarding healthy life-styles. For example, there is a positive correlation between intergenerational contact and the adoption of a healthier life-style.

An intergenerational perspective should be assumed in gerontological practice. Avoiding the exclusion of older people to isolated groups prevents ageism. Reciprocal activities that promote growth in both the adolescent and the elderly individual were observed in the answers reported, namely, as mutual emotional support.

Gerontology research groups have the opportunity to collaborate in raising awareness and educating youths about becoming and staying healthy in a society-wide sense, e.g., building a support network or intergenerational interactions [41].

Dialogue about intergenerational relationships should not be restricted to the family setting and should include the organizational political field because, in the context of modern society, the concept of generation extends in this way beyond the family [42].

Relationships between youths and the elderly, the transition from youth to adulthood and changes in family relationships, together with the conciliation of dependence and autonomy, require a collective plan. Therefore, youths seek independence from their relatives and opportunities in public domains such as work and school; similarly, the elderly seek ways to remain independent and autonomous at home [43]. Both processes raise complex questions about our society that generate the need for gerontological discussions beyond certain age groups.

\section{References}

1. Instituto Brasileiro de Geografia e Estatística (2010) Índicadores regionais

2. Borges CC, Magalhães AS (2009) Transição para a vida adulta: Autonomia e dependência na família. PISCO 40: 42-49.

3. Fruhauf CA, Orel NA (2008) Developmental issues of grandchildren who provide care to grandparents. Int J Aging Hum Dev 67: 209-230.

4. Strom RD, Strom PS (2015) Assessment of Intergenerational Communication and Relationships. Educational Gerontology 4: 41-52.

5. Skropeta CM, Colvin A, Sladen S (2014) An evaluative study of the benefits 
Citation: Santana RF, De Souza MT, Santo FHE, Silva ED, Martins NH (2015) Youth Participation in Home Care for the Elderly. J Gerontol Geriat Res S3:006. doi:10.4172/2167-7182.S3-006

Page 6 of 5

of participating in intergenerational playgroups in aged care for older people. BMC Geriatr 14: 109

6. Spira M, Wall J (2009) Cultural and intergenerational narratives: Understanding responses to elderly family members in declining health. Journal of Gerontological Social Work 5: 105-123.

7. Luy M, Flandorfer P, Di Giulio P (2015) Ageing in an aged society: experiences and attitudes of Catholic order members towards population ageing and older people. Ageing and Society 35: 1-36.

8. Van Den Heuvel WJ (2015) Value reorientation and intergenerational conflicts in ageing societies. J Med Philos 40: 201-220.

9. Kelley LS (2005) Minor children and adult care exchanges with communitydwelling frail elders in a St. Lucian village. J Gerontol B Psychol Sci Soc Sci 60: S62-73.

10. Veras R (2009) Population aging today: demands, challenges and innovations. Rev Saude Publica 43: 548-554.

11. Lima LD, Marques JC (2007) Relações interpessoais em familiares com portadores de doença de Alzheimer. PSICO 38: 157-165.

12. Pavarini SCI (2006) Quem irá empurrar minha cadeira de rodas? A escolha do cuidador familiar do idoso. Revista Eletrônica de Enfermagem. 8: 326-35.

13. Silva TCM, Amazonas MCLA, Vieira LLF (2010) Família, trabalho, identidades de gênero. Psicologia em Estudo 15: 151-159.

14. Falcao DVS, Bucher-Maluschke JSNF (2009) Cuidar de familiares idosos com a doença de Alzheimer: Uma reflexão sobre aspectos psicossociais. Psicologia em Estudo 14: 777-786.

15. Pratta EMM, Santos MA (2007) Família e adolescência: A influência do contexto familiar no desenvolvimento psicológico de seus membros. Psicologia em Estudo 1: 247-256.

16. Sands RG, Goldberg-Glen RS, Shin H (2009) The voices of grandchildren of grandparent caregivers: a strengths-resilience perspective. Child Welfare 88: $25-45$

17. Alwin J, Öberg B, Krevers B (2010) Support/services among family caregivers of persons with dementia perceived importance and services received. International Journal of Geriatric Psychiatry 25: 240-248.

18. Nazio T, Saraceno C (2013) Does cohabitation lead to weaker intergenerational bonds than marriage? A comparison between Italy and the United Kingdom. European Sociological Review 29: 549-564.

19. Taylor RJ, Chatters LM, Woodward AT, Brown E (2013) Racial and ethnic differences in extended family, friendship, fictive kin, and congregational informal support networks. Family Relations 62: 609-624.

20. Tsai FJ, Motamed S, Rougemont A (2013) The protective effect of taking care of grandchildren on elders' mental health? Associations between changing patterns of intergenerational exchanges and the reduction of elders' loneliness and depression between 1993 and 2007 in Taiwan. BMC Public Health 13: 567.

21. Willis R, Price D, Glaser K (2013) Ethnicity as a determining factor for instrumental support in mid and later life in England and Wales. The Journals of Gerontology Series B: Psychological Sciences and Social Sciences 68: 278-289.

22. Carreras JS (2002) Pedagogia Social Programas intergeracionale: educacion de personas mayores. Malaga: Aljibe.
23. Brandt M, Deindl C (2013) Intergenerational transfers to adult children in Europe: Do social policies matter?. Journal of Marriage and Family 75: 235-251.

24. Hughes ME, Waite LJ, LaPierre TA, Luo Y (2007) All in the family: the impact of caring for grandchildren on grandparents' health. J Gerontol B Psychol Sci Soc Sci 62: S108-119.

25. Barbetta PA (2008) Estatística aplicada às ciências sociais (5thed.) Florianópolis, Brazil: UFSC.

26. Creswell JW, Clark VL (2007) Designing and conducting mixed methods research. Thousand Oaks, CA: Sage.

27. Minayo MC, Assis SG, Souza ER (2005) Avaliação por triangulação de métodos: Abordagem de programas sociais. Rio de Janeiro, Brazil: Fiocruz.

28. Sánchez M, Hatton-Yeo A (2012) Active ageing and intergenerational solidarity in Europe: A conceptual reappraisal from a critical perspective. Journal of Intergenerational Relationships 10: 276-293.

29. Igarashi H, Hooker K, Coehlo DP, Manoogian MM (2013) "My nest is full:" intergenerational relationships at midlife. J Aging Stud 27: 102-112.

30. Musil CM, Gordon NL, Warner CB, Zauszniewski JA, Standing T, et al. (2011) Grandmothers and caregiving to grandchildren: continuity, change, and outcomes over 24 months. Gerontologist 51: 86-100.

31. World Health Organization (2005) International Health Regulations.

32. Brazil (2009) Estatuto do idoso (4thed.) Brasília, Brazil: Câmara dos Deputados, Edições Câmara.

33. Caldas CP (2003) Aging with dependence: family needs and responsibilities Cad Saude Publica 19: 773-781.

34. Fair CD, Delaplane E (2015) It is Good to Spend Time with Older Adults. You Can Teach Them, They Can Teach You: Second Grade Students Reflect on Intergenerational Service Learning. Early Childhood Education Journal 43: 19-26.

35. Haberkern K, Schmid T, Szydlik M (2015) Gender differences in intergenerationa care in European welfare states. Ageing and Society 35: 298-320.

36. Van Den Heuvel WJ (2015) Value reorientation and intergenerational conflicts in ageing societies. J Med Philos 40: 201-220

37. Chua PH, Jung Y, Lwin MO, Theng, YL (2013) Let's play together: Effects of video-game play on intergenerational perceptions among youth and elderly participants. Computers in Human Behavior 29: 2303-2311.

38. Schmidt C, Doll J (2010) Entre o avô e o neto. Relatos co-educativos.

39. Alves Junior ED (2000) O trabalho voluntário realizado por idosos numa universidade do tempo livre: tempo de lazer e segunda carreira. Motus Corporis 7: 11-40.

40. Andrew S, Halcomb EJ (2009) Mixed methods research for nursing and the health sciences (1sted.) Chichester, UK: Wiley-Blackwell.

41. Bergman MM (2008) Advances in mixed methods research: Theories and applications. Thousand Oaks, CA: Sage.

42. Ruschel AE, Castro OP (1998) O vínculo intergeracional: O velho, o jovem e o poder. Psicologia: Reflexão Critica 1: 523-539.

43. Sistema de Informação da Atenção Básica (SIAB) \& Datasus (2010) Indicadores demográficos do Brasil. 